\title{
Network pictures and supplier management: An empirical study
}

\author{
Catarina Roseira ${ }^{\mathrm{a}, *}$, Carlos Brito ${ }^{\mathrm{a}}$, David Ford ${ }^{\mathrm{b}}$ \\ a Faculty of Economics, University of Porto, Rua Dr. Roberto Frias, 4200-464 Porto, Portugal \\ ${ }^{\mathrm{b}}$ Euromed-Management, BP 921-13288 Marseille cedex 9, France
}

\section{A R T I C L E I N F O}

\section{Article history}

Received 3 November 2009

Received in revised form 30 June 2012

Accepted 11 July 2012

Available online 8 September 2012

\section{Keywords:}

Network pictures

Supplier management

Positioning

Interaction

\begin{abstract}
A B S T R A C T
It has been suggested that "network pictures" are a major factor in the development of companies' strategies and in their interactions with others. The purpose of this paper is to analyze how variations in companies' network pictures relate to their strategies and to their interactions with suppliers and with those suppliers' other counterparts. Four issues are particularly relevant in this context: the limits to the network pictures held by companies of their supplier networks; the consensus between individual and corporate network pictures; the positioning of companies and their expectations of suppliers; and the pattern of interaction between companies and their suppliers' counterparts. Drawing on a comparative analysis between two supplier network cases, the paper shows how companies' different network pictures drive their approaches to supplier networks. These approaches reflect the way that knowledge of suppliers' counterparts is gathered and distributed within companies, and also on the companies' interactions with suppliers' counterparts. The paper suggests that scanning supplier networks strictly on the basis of current pictures may limit the exploration of supplier networks' potential. We also propose the concept of an 'interaction net' as a key tool to enhance the understanding and management of networks.
\end{abstract}

(C) 2012 Elsevier Inc. All rights reserved.

\section{Introduction}

Business actors' views of the networks in which they operate, their "network pictures", have been shown to be a major factor in their interactions with others (Corsaro, Ramos, Henneberg, \& Naudé, 2011; Ford, Gadde, Håkansson, \& Snehota, 2003; Henneberg, Mouzas, \& Naudé, 2006; Leek \& Mason, 2009, 2010; Ramos \& Ford, 2011). It has been suggested that a broad network "vision" may enable a company to anticipate the strategic moves of direct and indirect counterparts, to foresee the effects of these moves on the company's network position, and to appropriately adjust its network strategy (Möller \& Halinen, 1999).

In the field of supplier networks, corporate success has been increasingly related to a company's relationships with its suppliers, as these relationships allow customers to specialize on their distinctive capabilities (Cousins \& Spekman, 2003; Gattorna \& Walters, 1996; Jarillo, 1988). However, many of the potential benefits and constraints of a company's supplier relationships are affected by the relationships those suppliers have with their other counterparts. Thus the ability of a company to manage these benefits and constraints is likely to be affected by the company's knowledge of the connections that its suppliers have with others. However, it is also likely that there will be severe limitations on the understanding that any one actor can have

\footnotetext{
* Corresponding author. Tel.: +3512255711 00; fax: + 351225505050

E-mail addresses: croseira@fep.up.pt (C. Roseira), cbrito@fep.up.pt (C. Brito), David.Ford@euromed-management.com (D. Ford).
}

of the dispositions and intentions of even its adjacent counterparts (Ford et al., 1998).

Despite the acknowledged significance of network pictures, there is still a paucity of empirical studies describing the range of network pictures held by actors and the interplay between those pictures and business interaction, particularly in the context of supplier networks (Ford \& Mouzas, 2010). In this context, the main purpose of this paper is twofold: Firstly, our aim is to increase our understanding of the pictures that business actors have of their supplier networks. In particular, we are concerned with actors' views of the relationships that their suppliers have with their own suppliers and with their other customers; Secondly, we aim to increase our understanding of how actors' pictures of their supply networks relate to the interaction that takes place between them and their suppliers.

The paper presents the cases of two industrial companies with contrasting pictures of their supplier networks and analyzes how these contrasting pictures relate to the two companies' different supplier strategies and interactions. Thus, this paper may help managers to reflect on the importance of interrogating the link between their network's pictures and their interaction strategies, making clear the implications of this link for their position and direction.

The paper is organized as follows: Firstly, the paper reviews the issue of network pictures as sense making devices within the business network literature and then focuses on the role of network connections in the context of supplier management. After this brief conceptual overview, the paper presents the research issues and framework for analysis, and the methodology used in this project. The two cases included 
in the empirical research are described and their findings discussed. The paper closes with the presentation of the main conclusions and managerial contributions.

\section{Managing and sense making in networks}

A stream of research in the literature on business networks has focused on actors' understanding and interpretation of the form and dynamics of the surrounding network in which they operate: its structure; processes and the likely effects of the actors' own and their counterparts' actions (Holmen, Håkansson, \& Pedersen, 2003; Ford \& Redwood, 2005; Mattsson \& Johanson, 1992). The concept of "Network Pictures" (Ford, Gadde, Håkansson, \& Snehota, 2011; Henneberg et al., 2006; Leek \& Mason, 2009, 2010) encapsulates this research and refers to the particular views held by actors of the extent, structure and operation of the network, as well as of the connections between the actors involved in it.

Different interpretations and definitions of the concept of "network pictures" have nevertheless been put forward (e.g., Henneberg et al., 2006; Ramos \& Ford, 2011), since it was first introduced by Ford, Gadde, Håkansson, and Snehota (2002) and Ford et al. (2003). A systematization of these different definitions can be found in Geiger and Finch (2010), as well as in Ramos, Henneberg, and Naudé (2012). The latter have identified three possible definitions for network pictures, depending on whether the interpretation of the network is carried out by the manager or by the researcher: network pictures as 1) actors' picturing of the network (i.e. managers' subjectively perceived network; Henneberg, Mouzas, \& Naudé, 2010); 2) researchers' picturing of actors' network pictures (i.e. network pictures as a research tool used by researchers to make sense of how managers perceive the network, as defined by Ramos and Ford (2011), or what Geiger and Finch (2010) define as 'mentalist network pictures'); or as 3) researchers' own picturing of the network (i.e. network pictures as a research tool used by researchers to have an objective view of the network), which corresponds to Geiger and Finch's (2010) definition of 'representationalist network pictures'; see, for example, Ford and Redwood (2005) for an exemplification of this application. According to Ramos et al. (2012), the combination or triadic epistemological dialog between these three definitions provides a kaleidoscopic view of the network. In this paper, the concept of network pictures is employed in the three ways identified by these authors: as researchers, we use network pictures as a research tool to carry out part of the empirical study, by grasping individual managers' perceptions on their surroundings, focusing this way on 'mentalist network pictures'. Moreover, we talk about network pictures as managers' subjective views. Finally, we use the concept of 'representationalist network pictures', as we try to build our own understanding of the network.

Network pictures are idiosyncratic and subjective, and are the outcome of each actor's individual interactions with a specific set of counterparts; these pictures correspond to each actor's interpretation of past experiences and future expectations about the network (Ford et al., 2003). Network pictures reflect discrepancies and inadequacies in the information available to individuals. The picture held by each actor and which forms a basis for its interactions is likely to vary depending on the problems or issues that it is addressing at a particular point in time. Network pictures are likely to vary between individuals in the same company and the concept of the network picture has been explored at the levels of the individual manager, the subgroup, the company, and the network (e.g. Leek \& Mason, 2010; Ramos \& Ford, 2011). It is suggested that each business actor has an idiosyncratic picture of the extent and characteristics of the network; of who does and should do what; of what works and does not work and of which actors to integrate or to exclude from their view of the network. The potential variations between individuals' pictures raise the issue of the extent of consensus between the views held by individuals and this forms one of the research issues addressed in this paper.

The views held by multiple individuals are crucial elements in determining the "network position" of a company, i.e., the role that it seeks to play in the network and the ways that it seeks to connect directly and indirectly with other companies (Wilkinson \& Young, 2002). A company's network position is an important element of its resource base, in which information about potential counterparts can be a key constituent (Gulati, 1999). The co-ordinates of network position both foster and constrain the company's possibilities for action (Gulati, Nohria, \& Zaheer, 2000; Håkansson \& Ford, 2002; Snehota, 2004) and influence the future development of its relationships. Thus, a company's strategic action influences and is influenced by the position of the company and of other actors and influences the connectivity and functioning patterns in the network (Mattsson, 2002; Powell, 1990; Ritter, Wilkinson, \& Johnston, 2004). However, the strategic direction of a single company is also determined in part by its counterparts (Ford et al., 2003), as that direction is the outcome of its own views and interpretations of the network, the views of its direct and indirect counterparts and its interactions with these. Companies' perceptions of the structure of the network are likely to change as they interact and their views of the network's scale may contract or expand through the exclusion or inclusion of other actors.

The partial views of the surrounding network held by companies may be considered on a number of levels (Anderson, Håkansson, \& Johanson, 1994): The narrowest level, the network context or "focal-net" (Möller \& Halinen, 1999) is comprised of those actors that the company considers to be relevant to its operations (Batt \& Purchase, 2004). An intermediate level, the "network horizon", includes the actors that companies know of but do not consider relevant as they are perceived to have no impact on their actions (Holmen \& Pedersen, 2003). Finally, the non-identified actors outside the actor's horizon may be considered as the "environment" (Holmen \& Pedersen, 2001), or the residual beyond the immediate context and the network horizon (Snehota, 1990).

Each actor's different levels of view are permeable and movements between them occur as counterparts gain or lose relevance (Batt \& Purchase, 2004) or as new actors emerge or are identified while others disappear. A company's ability to sustain or enhance its network position depends on its ability to "read" the network (Holmen \& Pedersen, 2003) or to construct an appropriate network picture for itself (Ford et al., 2003). For instance, a network picture based on a restricted horizon may prevent a company from acknowledging the existence of new competitors, while a misinterpretation of these new competitors' impact may lead to their exclusion from the company's network context. Thus, the inability to monitor and evaluate the network farther than its immediate relationships may make a company vulnerable to network dynamics emerging beyond its horizon.

\section{Supplier management in networks}

Each company's activities are embedded in a wider web of industrial resources and activities held and performed by different actors (Håkansson \& Johanson, 1993; Håkansson \& Snehota, 1995). A dyadic relationship provides a way of combining and developing the internal resources and activities of two actors, as well as exploiting the connections between each of these actors and the wider resource constellations of which they form part. Therefore, the evaluation of a supplier's potential is incomplete if it is restricted to the supplier's own bundle of internal resources and capabilities (Ritter \& Ford, 2004). A comprehensive supplier evaluation involves an analysis of a supplier's connections to others, as well as an evaluation of the implications of these connections for the customer. Dubois and Pedersen (2002) refer to two types of indirect supplier connections and their potential benefits: Firstly, the link to a supplier's other 
clients may produce economies of scale or technological innovations; secondly, the connections to a supplier's own suppliers extend the resources that may be accessed and influenced. Thus, Ritter et al. (2004) propose that managing interactions with counterparts not only directly but also indirectly is a key issue and a critical capability for a company to achieve its goals.

Network connectedness means that relationships may perform both direct and indirect functions (Ford \& MacDowell, 1999; Gadde \& Håkansson, 2003; Walter, Müller, Helfert, \& Ritter, 2003). Direct functions are those whose effects emerge from or are reflected in the dyadic relationships with direct counterparts and are generally associated with the connections between and the efficient exploitation of actors' resources and activities. Indirect functions relate to more complex issues such as the development of shared norms and values or the diffusion of new technologies and are likely to involve several direct and indirect counterparts. These multiple network functions are in line with the idea that exploring networks offers a highly effective means of enhancing learning, information dissemination and technological innovation (Bond, Houston, \& Tang, 2008; Powell, 1990). In the context of supplier management, the ability of suppliers to perform direct or indirect functions depends on their bundle of activities and resources and their set of relationships is an essential component. The evaluation of each supplier's relational context (part of its own position) needs to be supported by some kind of auditing of that supplier's network of suppliers, clients and other partners and relationships that connect them (Möller \& Törrönen, 2003).

The views that a company takes of the relationships of its suppliers with others are likely to be interconnected with the company's strategies towards those suppliers and the suppliers' own strategies and relational context. For example, a demand made by a customer for a supplier to be more flexible, may reduce that supplier's ability to respond to other clients (Dubois, Gadde, Hulthèn, Jonsson, \& Sundquist, 2003). Thus, a customer's analysis of changes in a supplier relationship intended to produce efficiency effects cannot be limited to the operational and technical dimensions of those changes. Instead, a broader analysis of how those changes relate to the supplier's own interests and network position will be necessary to determine that supplier's potential commitment to those changes and their consequent feasibility (Håkansson \& Ford, 2002; Holmen \& Pedersen, 2003). Knowledge of suppliers' networks is especially relevant when a company wants its suppliers to perform broader functions and to put into place changes that may involve indirect counterparts.

\section{Research issues and framework for analysis}

This paper is concerned with the network picture held by an actor of its surrounding network and with the interplay between that picture and the actor's supplier strategies and interactions. A number of specific research questions arise from this concern: what are the limits to the network pictures held by actors of their supplier networks; what are the links between individual and corporate network pictures; what is the influence of network pictures on a company's expectations of its suppliers (an important element of its positioning); how do these expectations translate into customer supplier strategies and how do supplier strategies relate to interaction with indirect counterparts? These questions are explored individually in the paper, and then integrated in the overall framework for analysis that guided the empirical research.

\subsection{Limits to the network pictures held by practitioners}

Despite the importance for an actor of understanding the position, relationships and role of its counterparts (Gulati et al., 2000), previous research has highlighted the limitations of actors' pictures of the surrounding network and in particular of their knowledge of their suppliers' connections (Blakenburg, 1992; Holmen \& Pedersen, 2001). One possible explanation for the discrepancy between theory and practice is the mediating role that suppliers may play in gathering, filtering and communicating relevant network knowledge for their customers, allowing those customers to operate in partial ignorance of network connections (Holmen \& Pedersen, op. cit.) beyond the first tier of the supplier network (Liu \& Brookfield, 2000). Other possible explanations may be a conscious attitude by actors to economize on the resources required to explore and make sense of the network or their ignorance of the potential impacts of indirect partners and relationships. Whatever the explanation may be, specific studies of what actors actually know of their suppliers' networks and of the reasons behind this knowledge are scarce and this calls for further investigation.

\subsection{Individual pictures, consensus and corporate pictures}

A second issue for management research concerns the variations between the network pictures of individual actors within a company. The configuration of an individual's network picture will be affected by its background, experience and the specific issues that the individual is addressing (Ford et al., 2003; Henneberg et al., 2006; Ramos, Ford, \& Naudé, 2005). The examination of business interaction at the level of individuals enables researchers to highlight differences between those individuals and subgroups in their views of interaction and to use those individuals as representatives of the approach to interaction of organizations. For example, Weick (1995) examined the transition of the sense-making concept from the subjective, individual and cognitive level of analysis into the social and organizational level. He suggested that although sense-making frameworks are individual, they are also a product of social interaction, which leads to a view of the organization as a "network of inter-subjectively shared meanings that are sustained through the development and use of a common language and everyday interaction" (Walsh \& Ungson, 1991, p.60).

Each company is made up of individuals with idiosyncratic and probably contradictory network pictures (Mattsson, 2002; Ford et al., 2003). These different pictures may emerge because individuals in different functional areas have access to network information that is quantitatively and qualitatively different. Additionally, individuals who share a common pool of information may acquire only the particular information that they need in a specific situation or which relates to their own stereotypes or preoccupations. However, by observing and analyzing companies' actions, reactions and re-reactions one may infer that one generalized organizational view, one 'apparent' network picture underpins a corporate actor's interpretation of the situation even though this apparently predominant network picture may simply be a reflection of the company's internal relationships of power and dependence among individuals or functions (Cook \& Emerson, 1978). ${ }^{1}$ Leek and Mason (2010) found differences in the network pictures that a company's employees held of supplier relationships and related those differences to the function and managerial level of employees. This paper complements this knowledge by further exploring the links between individual and organizational network pictures and knowledge of suppliers' networks.

In this paper we will refer to business actors in general, except when discussing individuals as respondents or as representatives of their companies, or when referring to issues specifically at the corporate level.

\footnotetext{
This section builds on Ramos (2008). Developing network pictures as a research tool: Capturing the output of individuals sense-making in organisational networks, Unpublished PhD, University of Bath, School of Management.
} 


\subsection{The expectations of customers}

Another research issue relates to the expectations that companies have of their suppliers, whether consensual or asserted by the customer alone (Ramos et al., 2005). It may be that the supplier functions that are sought by a customer are important in determining the information about suppliers' connections that are sought by that customer. Knowledge transfer requires interaction and effort (Bond et al., 2008) and companies that are pursuing innovation or wider network effects may seek more comprehensive knowledge of their suppliers' connections than those companies pursuing only efficiency effects. Similarly, it may be that a company devotes greater efforts to collecting information on those suppliers that are involved in innovation activities. Despite the importance attributed to relationship patterns in shaping the flows of information within networks (Gulati, 1999), we have only limited understanding of how companies' monitoring strategies are embedded in their interactions with suppliers. This gap in understanding is explored in this paper by examining the links between the goals/expectations that customers have of their suppliers, the relevance they attribute to suppliers' connections and their monitoring of these within their interactions.

\subsection{Interaction with indirect counterparts}

A further issue centers on the scope and form of a company's interactions with its indirect counterparts. Management research has attributed considerable importance for a company to manage its relationships with companies with which it is only indirectly involved (Ritter et al., 2004). But Ahonen and Salmi (2003) have suggested that companies take a passive attitude to these relationships. This leads to two research questions: Do companies interact with indirect partners in supplier networks and, if so, how? What is the connection between network pictures and the pattern of managerial interaction?

\subsection{Framework for analysis}

Fig. 1 illustrates an initial framework for analysis that builds on the issues discussed above, and which forms the basis for the empirical phase of this project.

This paper suggests a connection between the evolving network pictures held by individuals and corporate actors, their network positioning, their supplier strategies ${ }^{2}$ and their approaches to interaction. Network pictures will impact and be impacted by companies' strategies, positioning and their attitudes towards their own pictures and those of others (Ford et al., 2003). For example, actors who hold a view of a more inter-connected rather than an atomistic network and who acknowledge the impact of indirect relationships may take a broader view of their network positioning and develop strategies that take into account those broader connections.

Similarly, each company's network picture and positioning will be interconnected with its supplier management expectations/goals and the generic effects (e.g. efficiency, innovation, development) that the company observes and tries to achieve through the direct and indirect functions of its supplier relationships. In turn, its supplier goals will influence a company's positioning, the pictures held by its individual actors' of the dynamics of the network, as well as their interactions with specific suppliers.

Actors' network pictures may well be expressed in terms of the way that they believe the network or their suppliers "should" work

\footnotetext{
2 This empirical study is restricted to examination of the strategies, positioning and interaction between particular actors and those parts of the network referred to by them as their "suppliers". Of course the same conceptual structure applies in relation to the "customer strategies" of those particular suppliers or others (Hakansson et al., 2009).
}

(Ramos \& Ford, 2011). The way that companies build their own position by their interactions with suppliers is also interrelated with their strategy and network picture. In a very simple way, connecting to the right suppliers is a necessary, but not a sufficient condition to fulfill strategic goals. Finally, as its network picture evolves, an actor may change its evaluations of its own and its counterparts' positioning and adapt its strategies accordingly.

\section{Research methodology}

This project aims to clarify the knowledge that companies have of their suppliers' networks and how this relates to the companies' network pictures, their positioning, supplier strategies and their interactions with their suppliers and with suppliers' counterparts. An exploratory qualitative methodology (Lincoln, 1991; Strauss \& Corbin, 1990), grounded on a multiple case study design (Yin, 1994), was found suitable to address the research aims. Case studies have been found to provide the comprehensive understanding of the dynamics, interdependencies and complexities of relationships required in this case (Dubois \& Araujo, 2004, 2007). Two cases of industrial companies (i.e. a customer company) and their supplier networks were selected. Exploratory interviews revealed that the two companies held contrasting views on how competitiveness is created in their industries. These interviews also showed how the two companies attributed different roles to suppliers in support of their own operations, i.e., they held different network pictures (Ford et al., 2003). The fact that the cases represented different configurations of the same phenomenon (Ragin, 2000) fitted our research goals, as it allowed us to investigate possible (dis) similarities in the relationships among the constructs (Eisenhardt \& Graebner, 2007), i.e. if and how the differences in the companies' network pictures relate to their knowledge of and their interaction with their suppliers' counterparts.

Data was collected mainly through 62 semi-structured interviews conducted with 45 informants that were considered knowledgeable on the issues under study (Eisenhardt \& Graebner, 2007; Rubin \& Rubin, 1995) - 14 managers from the two customer companies, and representatives from 31 supplier companies for the two customer companies. Respondents were therefore selected using a purposive method (Denzin \& Lincoln, 2000; Stake, 1994). From each customer company, a top manager and several middle managers (14 managers in total) were interviewed. The middle managers held different supplier-related functions (i.e., R\&D, production, quality, procurement, purchasing and logistics). The aim of including respondents with different supplier-related functions was to capture a variety of perceptions and meanings (Dubois \& Araujo, 2007), as well as to investigate if there were any relevant differences in the knowledge held by each manager on their suppliers' networks (Leek \& Mason, 2010). These interviews allowed us to build a comprehensive insight into how each customer company managed its supplier relationships.

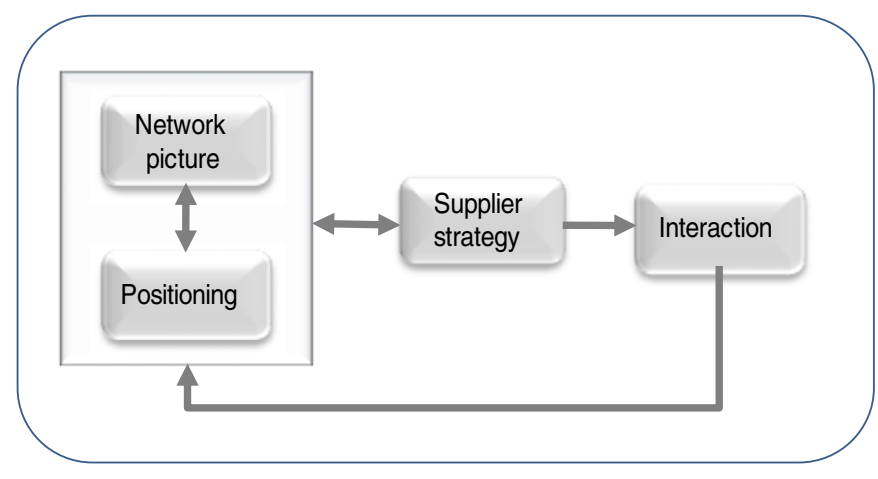

Fig. 1. Framework for analysis. 
In addition, 31 supplier informants (embodying the relationship between the supplier and the customer company for several years) were also interviewed, facilitating the capture of multiple perspectives (Jårvensivu \& Törnroos, 2010). The selection of the supplier informants followed a logic similar to that of 'theoretical saturation' suggested by Eisenhardt (1989), regarding the selection of case studies: the interviewing process stopped when the categories under study were already densified and saturated (Strauss \& Corbin, 1998), as adding new informants resulted in merely redundant data, and thus in minimal incremental learning (Glaser \& Strauss, 1967).

The semi-structured interviews (Punch, 2005), followed different scripts targeted at the customer company and the supplier informants (cf. Annex $\mathrm{A}^{3}$ ). Scripts were built around constructs grounded in the literature and embodied in the research issues and the framework for analysis, thus enhancing the study's reliability (Beverland \& Lindgreen, 2010). The use of common scripts also assured that the interview content matched the research "agenda" (Stake, 1995, p. 65), allowing for the comparison and pattern matching within and across the cases (Beverland \& Lindgreen, 2010). The interviewing process was organized in three phases:

Phase 1 A first round of interviews with the managers from the customer companies was designed to achieve two main goals: Firstly, to understand the evolution of customer companies' network pictures, positioning and strategy, and how these three elements were reflected in their interaction experiences and outcomes; Secondly, to understand how corporate strategies translate into supplier management strategies (i.e., goals and functions generally attributed to suppliers) and specifically in the relationships with the suppliers included in the study.

Phase 2 The 31 supplier representatives were then interviewed. The supplier informants were asked about the relationship between their company and the customer companies and this allowed us to understand the views of both dyad partners. In order to examine the suppliers' networks, informants were asked to identify their main suppliers and clients and the type of products/services the informants' companies were buying from or selling to. Informants were also asked to indicate if and how they were questioned about their counterparts by their clients and if and how the customer companies interacted with any of their counterparts.

Phase 3 Each middle manager from the customer companies completed a questionnaire listing each of their supplier's clients and the sub-suppliers of which they were aware. Respondents were also asked to explain how that knowledge was gathered and how relevant they thought it was and to identify and characterize existing interactions between the customer companies and the suppliers' counterparts. This third phase allowed us to compare the customer companies' mapping of suppliers' network with the suppliers' own mapping of their networks. This was in line with Leek and Mason's (2009) suggestion to compare the network pictures of both sides of dyads.

Visits to the firms' premises, press articles, internal documents and company websites were also used to gather, complement and triangulate data (Dubois \& Gadde, 2002). This was a key part of gaining in-depth understanding of a case (Yin, 1994), widening and deepening our understanding of the subject (Ritchie \& Lewis, 2003) and ensuring constructs' validity (Dubois \& Gilbert, 2010; Yin, 2009). The interviews varied between one to three hours each. They

\footnotetext{
${ }^{3}$ The present paper is part of a larger study on supplier management. The scripts in Annex A and the coded excerpts in Annex B (Tables B.1 and B.2) only include the parts of the complete documents that are pertinent to this paper. The interview's transcripts and cases' reports referred below pertain to the full research project.
}

were taped, and verbatim transcribed and each transcript was then sent to the corresponding interviewee for confirmation (Beverland \& Lindgreen, 2010). A database that included all the case documents (e.g. original and coded interview transcripts, internal documents, prints of websites information) for each case was created, providing an audit trail of the empirical research (Beverland \& Lindgreen, 2010; Gibbert, Ruigrok, \& Wicki, 2008). The interview transcripts were content analyzed (Krippendorff, 2004; Ritchie \& Lewis, 2003), and coded with the support of QSR NVivo, a software package for qualitative analysis. The coded transcripts were organized in a separate file database for each case. The coding followed a template based on categories derived from the research questions and the theoretical framework (Krippendorff, 2004; Miles \& Huberman, 1994). This provided a clear trail of evidence, enhancing the study's credibility (Fereday \& Muir-Cochrane, 2006), and internal validity (Gibbert et al., 2008). The codes used were as follows: customer company's network pictures; positioning - approach to positioning, perceived impact of suppliers' relationships; supplier strategy - goals/expectations; interaction - monitoring approach and interaction with supplier counterparts. An excerpt of each case coding is presented in Annex B (Tables B1 and B.2) for illustration. To strengthen the study's reliability, a sample of interviews was coded separately by two researchers to identify divergences in interpretation and coding (Krippendorff, 2004; Miles \& Huberman, 1994). No relevant differences were found between the two coders, pointing to the existence of (internal) replicability, which according to Krippendorff (2004), is the most important form of reliability. By assuring that the "data are obtained independent of the measuring event, instrument or person" (Kaplan \& Goldsen, 1965, p.83), we have thus reinforced the reliability of the study.

Each case was analyzed separately in order to understand how the several concepts were combined in each case (cf. Sections 6.1 and 6.2). Then, a comparative analysis of the two cases followed in order to identify and explain (dis)similarities between them (Dubois \& Araujo, 2007). The comparative analysis is summarized in Section 7. The individual case reports were sent to each case main informant (Adira's Production Manager and Vulcano's Purchasing Manager), that confirmed the reports' accuracy (Gibbert et al., 2008; Miles \& Huberman, 1994). Finally, an academic who had no involvement in the project, but is deeply familiar with its literature, reviewed the study full report and concluded that no significant changes were needed. This independent evaluation furthered our confidence in the study's construct validity (Gibbert et al., 2008) and reliability (Miles \& Huberman, 1994).

\section{The cases}

The two cases reported here illustrate a number of differences between the companies' network pictures, their interaction and their supplier strategies. The two companies are also positioned differently in the network in relation to their suppliers and in their interconnected relationships with their own customers and corporate owners.

\subsection{Adira}

\subsubsection{Network picture}

Adira was founded in 1956 and is currently the largest Iberian machinery manufacturer. The company's network picture relates closely to its interpretation of how competitiveness is created in its industry: Adira strongly believes that the success of its most able competitors results from their internal capabilities. It attributes a limited role to suppliers in this success, because it shares some suppliers with those competitors. Adira seeks to position itself as the sole counterpart for those companies that buy its machines. In order to achieve this purpose, Adira feels the need to have wide internal knowledge 
and productive capabilities. This requirement is reinforced by Adira's view that its suppliers and distributors have very limited technical abilities. Furthermore, Adira generally believes that what happens in the relationships between its suppliers with their own suppliers or clients, does not affect it. The company has two main types of suppliers: Component Suppliers and Subcontract Suppliers. Component Suppliers range from multi-brand representatives to national agents or local subsidiaries of companies like Bosch or Siemens, selling standardized materials and products. Subcontract Suppliers range from micro to medium-size companies that manufacture parts to Adira's specifications.

For its 13 suppliers included in this study, Adira's respondents named in total 39 sub-suppliers and 39 of the suppliers' other clients. Adira's respondents also thought that a further 10 suppliers' clients and 10 sub-supplier relationships existed, based on the informants' assumptions about the way the industry works and on the existing relationships among Subcontract Suppliers. However, the existence of these relationships was denied by the suppliers. None of the other suppliers' clients referred to by Adira were identified by those suppliers as being their main clients.

The number of identified counterparts was significantly higher for Component Suppliers than for Subcontract Suppliers. This distinction is especially strong when suppliers' clients are involved: 32 clients of Component Suppliers were named against 7 clients of Subcontract Suppliers. There was also a clear difference between the knowledge exhibited by respondents involved in the different relationships: Those involved with Component Suppliers consistently identified more suppliers' counterparts than those that managed Subcontract Suppliers. For Component Suppliers, the figures were; CEO - 52 counterparts, Engineering Manager - 38 and Components Buyer 30. For Subcontract Suppliers, the figures were Production Manager 8 suppliers' counterparts, the Logistics Manager - 9, the Subcontracted Buyer -2 and the Quality Manager - 0 .

\subsubsection{Positioning}

During its five decades of existence, Adira has strived to strengthen its autonomy and independence from its various counterparts. To achieve this, Adira invested in developing activities and capabilities backward and forward from its initial manufacturing activities. Adira uses suppliers to pursue efficiency functions: low costs, high flexibility, availability and product quality/reliability.

\subsubsection{Supplier strategy}

Adira's strategy towards its suppliers relates closely to its view of their limited importance for its success and development and to its 'egocentric' network picture. Adira's view is that although knowing who the sub-suppliers are may help to "have an idea about the quality they can supply us with" (Adira CEO), the company believes that it has ways of doing this without asking its suppliers. The experience from long relationships with suppliers and the specification process are generally seen as an effective way to evaluate the quality of their sources. Supplier reputation is also considered a good proxy for quality in the sourcing network. For Adira, suppliers' reputation is more strongly associated with their clients than with their sub-suppliers. Knowing who the clients are provides Adira with a good idea of the suppliers' network positioning and of their credibility and reliability. This may be important when suppliers or their products are new and, consequently, when there is no relationship experience that can be used to minimize the risk of adoption. In some situations, the name of some highly reputed clients of Component Suppliers can be used to guarantee the quality of Adira's machinery and its reputation.

\subsubsection{Interaction}

Subcontract Suppliers buy mostly raw-materials (frequently from Adira) and the parts, material and sometimes the production processes are specified by Adira. This provides Adira with strong control over their purchases and productive processes. The small number of clients identified in the cases of Subcontract Suppliers is because some of these suppliers have an almost exclusive relationship with Adira, and also because Adira places little value in knowing who their other clients are. Some of the company's Component Suppliers are commercial representatives of international manufacturers and consequently their sub-suppliers and respective brands and products are necessarily publicized. When Component Suppliers are themselves the manufacturers, their network connections are much more opaque and only a few of their business partners were identified. Adira's Engineering Manager stated, "It is rather invisible (...) we don't have much access to the suppliers of our suppliers. It happens when we disassemble their products and find out that that they are buying here and there, but we don't have much information ... we don't know who they are buying from". However, the fact that the suppliers do not "exhibit" their suppliers is considered normal and Adira has the same attitude. As the same informant explained, "We also don't tell [who our suppliers are]". Suppliers confirm that they are not normally asked about their own suppliers and in some cases, are unwilling to provide that information. According to one of these suppliers, "No [they don't ask], and I wouldn't tell them! Let them search if they want... Deep down, secrecy is the soul of the business". Adira does not have a systematic approach to collect information on its suppliers' counterparts. Generally, this information is collected informally through trade fairs, supplier catalogs or informal conversations with suppliers or other business partners.

Adira does not interact with any of its suppliers' counterparts. However, the company tries to influence those connections, especially in the case of the smaller Subcontract Suppliers. These suppliers are defined by Adira's CEO as its "external workstations", expressing its view that they are almost completely adapted and dedicated to the requirements of Adira. Formally, Subcontract Suppliers are only required "not to work with our competitors" as Adira fears that suppliers may give them the designs and specifications of its parts. In practice, the small size, diversity and frequent changes to Adira's orders, together with the pressure to consider them a priority, leave these small suppliers no space to find new customers. In the case of the Component Suppliers, for which products are standardized, there is no risk of suppliers passing on sensitive information and they are free to work with Adira's competitors. In the exceptional cases where components are adapted to Adira's needs, the company minimizes the information given to the suppliers. From its long experience with the Component Suppliers, Adira believes that the relationships that suppliers have with other clients, including competitors, have no impact on their relationship with Adira and this gives the company additional reasons not to invest resources in trying to know or to influence them.

\subsection{Vulcano}

\subsubsection{Network picture}

Vulcano was founded in 1977 to produce gas-fired hot water systems under a license from Bosch, which now owns the company. This ownership relationship appears to be central to Vulcano's network picture. Vulcano has always faced two sources of competition: one from other Bosch companies that produce similar products, and one from competitors outside of Bosch. Consequently, Vulcano has emphasized the constant evolution of its capabilities and resources in order to strengthen its position in both arenas. At the same time, its initial link and later integration into Bosch offered Vulcano an easy access to a huge pool of resources and capabilities, namely information about potential suppliers that 'fit' their needs (Gulati, 1999). In 1993, Vulcano was designated Bosch's competence center for gas-fired hot water systems, making innovation and development capabilities even more central to its future. Since the beginning, the company has assumed that its success depends on its ability to 
forge links with external actors able to add value to its internal activities. It invests in an external organization that allows it to "integrate suppliers' capabilities as if they were ours". Vulcano strongly acknowledges its interdependence with its direct and indirect counterparts and is heavily involved in evaluating these links as part of its evolving view of the wider network.

The four interviewed middle managers identified counterparts of all their 18 suppliers included in this project; a total of 54 suppliers' clients and 39 sub-suppliers. The managers' knowledge of their suppliers was consistently higher in the case of suppliers that were involved in product development than those that were not. The sub-suppliers and suppliers' clients identified by Vulcano match those indicated by suppliers as their main business partners, reflecting a high consonance between their respective network pictures. The distribution of knowledge was uneven among Vulcano's managers. Logistics and Quality Managers were aware of 11 and 9 suppliers' partners, respectively. The Development Manager identified 22 counterparts and the Purchasing Manager 87. The Purchasing, Logistics and Quality Managers dealt with all the suppliers in this research project, but the Development Manager only knew and dealt with the six suppliers that are involved in the development project he lead.

\subsubsection{Positioning}

The company's supplier base is comprised of medium to large local or foreign companies that have or must develop "a minimal structure of resources in quality, logistics, manufacturing, development and management" (Vulcano Board Director).

\subsubsection{Strategy}

Traditionally, Vulcano specified all parts' details (functions, materials, dimensions) and suppliers manufactured them, so-called "make to print". More recently, Vulcano's development team has been actively seeking suppliers' assistance to develop parts in areas in which it lacks knowledge and does not wish to develop it. Vulcano expects all suppliers to "proactively produce and suggest new solutions in terms of product specifications, materials or processes" (Vulcano Purchasing Manager), creating the opportunity for joint value creation as suggested by Jarillo (1988). When selecting and evaluating suppliers, factors such as quality, price, flexibility and continuous sourcing are important, but dynamic and indirect capabilities are the main differentiating factors. The extent of suppliers' other customers is an important selection criterion, as it indicates if suppliers have enough critical mass to undertake the investments required to support the Vulcano's goals. Additionally, suppliers' relationships with other customers are seen as a source of diversity and learning opportunities that are essential for keeping suppliers up-to-date technologically and for fostering their innovation ability; this may reflect positively on Vulcano. This is in line with the view of the network as a way to access valuable information from indirect sources (Bond et al., 2008). The Purchasing Manager stated that, "suppliers' potential to do this or that is determined by their capabilities and many times by their portfolio of clients" that expose them to "new markets, new technologies, new parts and new demands", and assures that "their know-how is constantly being refreshed". These benefits may be counterbalanced by an eventual loss of the importance of the customer company vis-à-vis the suppliers due to their commitment to other more powerful clients.

\subsubsection{Interaction}

The variations in the pictures of the different managers at Vulcano reflect their relative importance in the company's interactions with suppliers. Purchase management is considered a strategic function at Vulcano and its manager has the predominant role in all the main supplier decisions; also, supplier information is collected or coordinated mainly by this area. The Purchasing Manager is the only informant with direct responsibility and access to the "Supplier Profile File" that includes information about supplier's main clients, their respective industries and purchases. The "Supplier Profile File" is updated on the basis of supplier information whenever relevant changes occur. The Logistics and Quality informants' lower level of knowledge relates to the more operational nature of their tasks and also to the company's policy of making suppliers fully responsible for managing their own supplier network logistics and quality issues. The greater network knowledge of the Development Manager seems to confirm the association suggested earlier between the exploration of indirect capabilities required by product development and a wider knowledge of supplier networks. Thus, Vulcano shows clear variations in the network pictures held by managers in different functional areas.

Because of the acute positive and negative effects of suppliers' clients, Vulcano tries to monitor those connections closely. Subsuppliers are not granted the same attention. Vulcano believes that their effects on its business activities are less relevant and that it is possible to control the supplier network fairly well through the specification process. In this context, the Purchasing Manager explained that, "We know their supplier structure quite well, but it is not dramatic because all is well safeguarded through our specifications" and adds that "... I really don't care about where he buys, I probably know it, but it does not interest me that much as everything is specified right from the start". Furthermore, the experience emerging from the long-term relationships with most of its suppliers, the regularity of supplier quality auditing and Vulcano's own quality control system provides the company with a level of confidence in suppliers' sources that makes further knowledge dispensable. Suppliers confirm that Vulcano does not generally ask them to provide information on the sub-suppliers.

Vulcano has no interaction within its suppliers' portfolios of clients. However, it tries to influence this portfolio in two apparently opposite ways: Firstly, it makes clear to suppliers the risks and penalties suppliers will incur if they reduce their commitment to Vulcano as a result of their relationships with other clients. Secondly, Vulcano stimulates suppliers to find new and different clients, "forcing them to a kind of strategic development" (Purchasing Manager). In Vulcano's view, widening the portfolio of clients induces efficiency and innovation and safeguards the feasibility of investments in resources and new capabilities, as seen earlier. Furthermore, it also develops relational capabilities, namely the ability to understand the clients' businesses and complementarities, which is considered an essential element of a supplier's value. Vulcano may designate sub-suppliers to suppliers. In some cases, the selection of sub-suppliers is done via the Thermotechnik division of Bosch, which includes Vulcano. Thermotechnik concentrates the purchases of its several companies and negotiates contracts with common suppliers, obtaining major cost reductions that are available to all Thermotechnik companies and their suppliers. In other cases, Vulcano selects suppliers to develop specific parts of a component and when the development process is over, they become sub-suppliers of the supplier in charge of assembling the component. Suppliers are not obliged to buy from the sub-suppliers designated by Vulcano, but if they choose to work with other sources, these must be previously approved by Vulcano. Suppliers are normally willing to accept the client's 'imposition' as designated sub-suppliers have already passed Vulcano's selection criteria, and normally charge lower prices. Vulcano wishes to keep its interaction with sub-suppliers restricted to the development and negotiation phases. Suppliers must take full responsibility for managing their sub-suppliers. If a supplier calls for Vulcano intervention, this is seen to be a limitation to the supplier's capabilities that results in added costs and management complexity for Vulcano.

\section{Case analysis}

In this section, we discuss some of the main findings from the two cases in the light of the research issues that were raised earlier. These findings are synthesized in Table 1. 
Table 1 suggests wide differences between the two companies' network pictures and approaches to positioning, supplier strategy and interaction. Adira has an atomized view of the network that limits its acknowledgment of network interdependencies and effects. Vulcano's view of itself as deeply integrated within the network emphasizes its broad, interdependent and developmental relationships with its suppliers. The companies also have different strategies to monitor the wider network.

Below, we analyze and contrast for the two cases the different research issues in this project's research framework. These are associated with: strategy and customer's expectations regarding suppliers; the limits of network pictures of supplier networks, the overlaps between individual and corporate network pictures; the link between customers' expectations and supplier strategies, namely the monitoring approach and interaction with indirect counterparts.

\subsection{Expectations held by customers}

The cases reveal that the functions that customer companies seek from suppliers condition the way those companies evaluate their suppliers' connections with their other clients and suppliers. Adira focuses on efficiency effects and considers that suppliers' relationships are irrelevant in the production of those effects. This reinforces its low interest in these relationships. In contrast, Vulcano is convinced that suppliers' ability to perform efficiency and development functions is conditioned by their network connections. Therefore, Vulcano sees suppliers' networks as a reservoir of synergies, knowledge and innovation (Powell, 1990) that can be explored through the suppliers by adopting an active approach to identifying them. Both of the case companies believe that their previous experience with suppliers and knowing who the suppliers' clients are can help them to evaluate their current capabilities, e.g. their performance in quality or logistics. The suppliers' more dynamic or indirect capabilities that are explored by Vulcano cannot be evaluated using previous experience or by knowing who suppliers' clients are. Instead, this requires wider knowledge that includes the characteristics of suppliers' relationships with other clients.

\subsection{Limited network pictures of practitioners}

Overall, the customer companies have a more comprehensive picture of the network than those described in previous research conducted by Blakenburg (1992) and Holmen and Pedersen (2001). It is clear that Adira and Vulcano have different views on the relevance of what we would describe as a comprehensive picture of the

Table 1

Network pictures, positioning, supplier strategy and interaction.

\begin{tabular}{|c|c|c|c|}
\hline \multicolumn{2}{|c|}{ Framework dimensions } & \multirow{2}{*}{$\begin{array}{l}\text { Adira } \\
\text { Atomized } \\
\text { static }\end{array}$} & \multirow{2}{*}{$\begin{array}{l}\text { Vulcano } \\
\text { Inter-connected, } \\
\text { evolving }\end{array}$} \\
\hline Network pic & tures & & \\
\hline \multirow[t]{2}{*}{ Positioning } & Approach to positioning & $\begin{array}{l}\text { Individualistic, } \\
\text { ego-centric }\end{array}$ & $\begin{array}{l}\text { Collectivist, } \\
\text { integrator }\end{array}$ \\
\hline & $\begin{array}{l}\text { Perceived impact of } \\
\text { suppliers' relationships }\end{array}$ & Very low & $\begin{array}{l}\text { High: both positive } \\
\text { and negative }\end{array}$ \\
\hline Strategy & $\begin{array}{l}\text { Orientation of supplier } \\
\text { strategy (expectations) }\end{array}$ & $\begin{array}{l}\text { Direct } \\
\text { functions }\end{array}$ & Indirect functions \\
\hline \multirow[t]{8}{*}{ Interaction } & Monitoring approach & $\begin{array}{l}\text { Informal and } \\
\text { rather passive }\end{array}$ & $\begin{array}{l}\text { Active: formal and } \\
\text { informal mechanism }\end{array}$ \\
\hline & Number of identified & Clients: 39 & Clients: 54 \\
\hline & suppliers' counterparts & Suppliers: 39 & Suppliers: 39 \\
\hline & Average number of identified & Clients: 3 & Clients: 3 \\
\hline & counterparts per supplier & Suppliers: 3 & Suppliers: 2.2 \\
\hline & Suppliers' counterparts & Maximum: 51 & Maximum: 87 \\
\hline & identified per informant & Minimum: 0 & Minimum: 9 \\
\hline & $\begin{array}{l}\text { Direct interaction with } \\
\text { indirect counterparts }\end{array}$ & None & $\begin{array}{l}\text { Marginal (only with } \\
\text { sub-suppliers) }\end{array}$ \\
\hline
\end{tabular}

network, having therefore developed monitoring strategies that are consistent with those views. The average number of clients per supplier that was identified is similar in both cases, and the average number of sub-suppliers is higher in the case of Adira. However, on the basis of the companies' network pictures and attitudes, the opposite would have been expected. Nevertheless, a closer examination reveals some details that may clarify this apparent paradox. First of all, it is necessary to recall that there are discrepancies between the networks drawn by Adira and the ones drawn by its suppliers, as some of the identified relationships did not exist, while other had existed but had been terminated. This discrepancy emphasizes the individuality of network pictures, and that these individual views, rather than any objective reality form the basis for interaction (Ford et al., 2003). Furthermore, the majority of the sub-suppliers are international manufacturers that are represented in the domestic country by four of Adira's suppliers, making it almost impossible for the customer not to know them. When direct suppliers are themselves the manufacturers, Adira was in some cases unable to identify a single indirect supplier. In the case of Vulcano, the network drawn by the company is consistent with the connections reported by the suppliers.

Thus, network horizons that appear similar due to the number of indirect actors included may hide significant differences in managers' knowledge of those indirect actors. This suggests that it is necessary to consider other variables apart from the number of indirect partners identified by companies in order to obtain a finer definition of companies' actual network pictures (Ramos et al., 2005). Furthermore, while both companies illustrate broader network pictures of supplier networks than those described in previous research, this reflects more on their network horizons than on their network contexts, which remain restricted. These network contexts may also conceal different interaction strategies. While all actors at this level may be considered relevant to a company's actions, only a proportion of those actors is likely to be the focus of their interaction.

\subsection{Individual pictures and consensus}

Information on suppliers' connections is rather unevenly distributed between individuals within each customer company, and knowledge is concentrated in those who play major strategic and development roles in supplier management. These differences in knowledge are manifested in the different network pictures of respondents from different functional areas. The cases showed no evidence that the companies attempted to diffuse information about the network to more operational staff, to examine divergent perceptions, or to work towards consensus.

\subsection{Monitoring approach}

Both case companies have more knowledge of their suppliers' other clients than their knowledge of their sub-suppliers. Moreover, both companies consider client knowledge to be more relevant to their operations than sub-supplier knowledge. The lower importance attributed to the latter may be explained by their low value as warrantors of suppliers' performance or as potential sources of learning and also by the use of the indirect control mechanisms already discussed (specification processes; previous experience with suppliers and their products; suppliers' image and positioning).

The situation is quite different when suppliers' clients are considered. Here, the aims and strategies of the two companies are closely associated with their evaluations of suppliers. Adira only evaluates static performance and it considers that knowledge of who the suppliers' clients are is sufficient for this. In contrast, Vulcano believes that the dynamic performance of suppliers may be fostered by synergies produced within their relationships with other clients. But Vulcano considers that those same relationships are potentially damaging to 
the influence that the company may have over its shared suppliers. In this situation, Vulcano believes that its knowledge of who the suppliers' clients are is insufficient for its evaluations. Vulcano also considers it useful to know the type of resources and capabilities that suppliers are using or creating in their relationships with other clients and what is the importance of those clients to the supplier's business. Adira has no formal procedures to acquire knowledge through its interaction with direct or indirect counterparts, abandoning this passive attitude only occasionally in order to reduce the risks associated with the adoption of a new supplier or product. Vulcano takes a more active approach, which is embodied in formal procedures such as the "Supplier Profile File" and in its requirement of suppliers to update Vulcano about all the relevant changes in their client portfolio.

\subsection{Interaction with indirect counterparts}

Interaction with suppliers' counterparts is non-existent or marginal in the two company cases. The companies' interest in exerting indirect influence relates to their respective views of network effects and their evaluation of the possibility and utility of interacting with suppliers' counterparts.

\subsection{Interaction with suppliers' clients}

Banerji and Sambharya (1998) suggest that the links between a company's suppliers and the suppliers' other clients may affect the dependency relationship between that company and those suppliers. The case companies interpret network effects involving innovation in dissimilar ways: Adira thinks that the innovative knowledge that generates competitive advantages is created within itself and that it must be protected from being diffused through suppliers. Vulcano sees the diversity present in the suppliers' network as a source of knowledge and innovation. Vulcano's suppliers are encouraged to find new clients from different business contexts in order to foster the "multiplying effects" of network diversity. Both Adira and Vulcano also see the connections between their suppliers and their other clients as a potential threat to the suppliers' commitment towards their companies. But the companies deal with this threat in different ways: Adira reinforces its intent to limit network effects by pressuring smaller suppliers not to have other clients. Vulcano faces a particular problem: How to achieve network potential, fostered by the development of suppliers' network of clients while simultaneously assuring suppliers' commitment. Vulcano tries to solve this problem in a variety of ways, namely by building relationships that interest and mobilize its suppliers, monitoring changes in customer-supplier positioning and penalizing "disloyal" suppliers by reducing their supply "quotas" or even by eliminating them. Its actions with respect to its suppliers' other clients are always indirect, and assume the nature of an "empowered influence" designed to mobilize suppliers to adopt a network posture that serves the interests of the customer. It seems that the low visibility of operational and resource connections tends to reduce the legitimacy of any direct intervention by the customer companies.

\subsection{Interaction with suppliers' suppliers}

Both companies consider that sub-suppliers have limited effects on their business. However, they have a stronger involvement with the sub-suppliers of their suppliers than with the suppliers' clients. In Vulcano's case, the connection with sub-suppliers is made directly through their appointment to the suppliers. There is also an indirect connection through the specification process of parts or materials in the cases of both Vulcano and Adira. The connections between the activities and resources of the participants in the network mean that the impact of sub-suppliers on suppliers' performance, and consequently on the performance of the customer company, is rather straightforward and visible. This chain of effects seems to legitimize the intervention of the customer company and explains why suppliers accept and sometimes welcome that intervention.

The cases indicate that companies' unwillingness to intervene directly in the relationships that suppliers have with their counterparts appears to be grounded in two main reasons: Firstly, intervention collides with the efficiency goals that both case companies pursue, given that dealing with suppliers' partners is resource consuming and adds to the complexity of supply management; secondly, the need to intervene indicates a limit to suppliers' indirect capabilities, namely their relational capabilities. Companies often seem to expect suppliers to perform some kind of "isolation role" (Holmen \& Pedersen, 2003) between the client and their own networks by filtering and transmitting to the client only the information and knowledge that is adequate and useful for its activities. In addition, suppliers must also be able to manage their relationships within their networks in a way that fits or at least does not harm the client's interests. The inability of suppliers to perform one or both of these tasks may originate costs and problems for the customer company, and contribute to the devaluation of suppliers.

\section{Conclusions}

This paper is part of a growing stream of research on sense-making in business networks. Previous work has used the concept of network pictures either as the actors' picturing of the network (e.g. Henneberg et al., 2010); as the researchers' picturing of actors' network pictures (e.g. Ramos \& Ford, 2011); or as researchers' own picturing of the network (e.g. Ford \& Redwood, 2005). In this paper, we have mainly used the two first interpretations and to a lesser extent the third. We cannot and do not claim to have built an objective view of network, but we have tried to capture its main characteristics, for instance by contrasting the views of the multiple informants from the customer and supplier companies. We believe that the triple use of the concept provides a kaleidoscopic view of the network (Ramos et al., 2012), and is a feasible and useful way to apply the concept and to carry out research in business networks.

The two cases companies analyzed in this paper may almost be considered as "ideal types" in their respective internal and external orientation to the activities, abilities and resources that define their long term direction and position (Hakansson et al., 2009). In this sense, the paper highlights the role of network pictures as a potential managerial device for network positioning, as well as a base of interaction between business actors. Previous researchers emphasized the importance of understanding the relations between network pictures and interaction (e.g. Hakansson et al., 2009; Ramos, 2008; Ramos \& Ford, 2011), but these relations have been studied only in one direction: how network pictures affect interaction. In this study, we develop this further and explore the two-way relationship, analyzing how interaction feeds back to companies' network pictures and influences their evolution.

The two cases extend previous work on network pictures and on supply networks (e.g. Batt \& Purchase, 2004; Ford et al., 2003; Holmen \& Pedersen, 2001, 2003) and add to the understanding of the evolving nature and the dynamics of network pictures. The paper suggests that a company's pictures and positioning influence supplier interactions on two levels: its approach to monitoring supplier networks and its interactions with suppliers' and with suppliers' counterparts. With reference to the monitoring approach, the paper furthers our understanding of the factors underlying the limits to practitioners' pictures of supplier networks. Firstly, the study reveals that companies' network pictures and goals (i.e. expectations) regarding suppliers determine which information is relevant and should be searched for, as well as which aspects are non-relevant and should be disregarded. As information scanning is based on companies' current pictures, this means that companies seek information on what they "know that they don't know", with apparently little 
regard to more exploratory information gathering into areas in which they "don't know what they don't know"!

Moreover, companies' pictures appear to be a strong and rather durable framework that guides the interconnected processes of cognition and interaction. The case companies were shown to have a parsimonious approach to supplier networks, which makes information gathering neither erratic nor random. In fact, our findings suggest that ignorance of suppliers' connections seems to be the result of a conscious choice. This choice seems to be only partially explained by the companies' reliance on suppliers' "isolation" role, as suggested by Holmen and Pedersen (2001). This paper reveals that companies tend to replace direct network monitoring with indirect, more economic, and equally effective mechanisms. Additionally, the study also identifies specific mechanisms of sourcing control in the case of sub-suppliers (i.e. specification processes, relationship experience, quality control, supplier reputation) which make direct and detailed interaction with this part of the surrounding network superfluous.

The research reported in the paper indicates that while companies' pictures condition their network scanning and interaction, interaction with suppliers also seems to feed into network pictures. We suggest that these interconnections can provide an explanation to why network pictures may 'ossify' (Ramos \& Ford, 2011). An inter-connected network picture, such as that found with the case Vulcano may present a lower risk of ossification that an atomized one as was the case for Adira. A view of an inter-connected network seems to fuel active strategies to "read" the network and to acknowledge new network insights through interaction with suppliers. In turn, those insights feed the company's network picture, promoting its evolving nature. A more atomized view of the network seems to result in a less active strategy to read the network and in a reduced capability to seek for and recognize change through the interaction process. In this case, interaction will have fewer chances of producing change in the company's network picture, leading to a more static and ossified view. Thus, the cases indicate the dangers of corporate scanning of the network that is limited to current, or even previously identified issues, problems and companies. To prevent these dangers, it is advisable for companies to pursue a broader and more exploratory monitoring of the network, stretching beyond areas of immediately defined relevance.

This paper increases our knowledge of the actual management of indirect interactions within two main findings: the marginal nature of interaction with indirect actors and the apparently paradoxical dissociation between the relevance attributed to suppliers and the interaction with them. The paper also points to some explanatory factors for these findings. Firstly, companies' network pictures expressed in terms of how connections among business actors should be organized and managed is reflected on their restricted interaction net. Managers may prefer to deal with a rather narrow interaction net because they associate the enlargement of the net with reduced efficiency. However, this research also shows that an unwillingness to interact with suppliers' counterparts does not mean a lack of interest in influencing them. Companies may try to pressurize suppliers to develop those relationships in the way that best fits their interests. When suppliers' counterparts are thought to have beneficial effects, suppliers may be stimulated to expand their network connections. When effects are seen as negative, customer companies try to minimize those connections. Secondly and perhaps surprisingly, the case companies tended to interact less with those indirect actors about which they have more information and which they consider to be more relevant (suppliers' clients in both cases). Thus, our cases suggest that knowledge and relevance do not necessarily breed interaction. Suppliers' clients were considered especially important due to the positive effects they could have on suppliers' capabilities and resources, as well as the negative effects they could have on suppliers' commitment to the customer company. However, because these suppliers' clients were located outside the customer companies' immediate "supply-chains", and had no direct impact on their performance, there was little interaction with them. Sub-suppliers were not considered to be significant, but the pattern of activities and resources that linked the actors in the supply network made it easier and more acceptable for customers to intervene directly or indirectly in this context. These findings on the interaction with indirect counterparts may further the discussion on the actual importance of managing indirect interactions to achieve companies' goals, as claimed by the literature (e.g. Ritter et al., 2004) and on the difficulties of actually doing it.

The study also deepens our understanding of corporate and individual pictures. In line with previous studies (e.g. Henneberg et al., 2006; Leek \& Mason, 2009; Ramos et al., 2005), the research highlights the disparity of individual pictures within companies. The companies' parsimonious approach to the network is reflected in the way information is distributed among individuals in each company and is used in their interactions with suppliers. Knowledge of suppliers' connections is concentrated in people playing strategic or development roles and is not passed on to other people as it is not considered a valuable resource for their operational activities. It should also be noted that as expected, some overlapping between individual pictures within each case company was found. These overlaps do not stem from information sharing mechanisms, e.g. as the communication channels found by Leek and Mason (2009), but seem to be the coincident outcomes of separate interactions of individuals with the suppliers. Overall, the claims by Leek and Mason (2009) that individuals' pictures of dyadic relationships are linked to their functions and hierarchy levels seem to hold in our study of more comprehensive supplier network pictures. Still, some individuals at the same hierarchical level but with different roles (e.g. Vulcano's development vs. logistics managers; Adira's engineering vs. production managers) held rather different information of suppliers' connections. This fact suggests that individuals with roles linked to development goals may build more comprehensive pictures of supplier connections than those individuals pursuing efficiency effect. Further studies are required to confirm this idea.

Regarding corporate pictures, our cases showed no signs of efforts to share information or to build consensus about suppliers and their networks (in line with Henneberg et al., 2006; Ramos et al., 2005, among others). It should be noted that individual pictures are expressed mainly in the different knowledge of supplier counterparts (e.g., number of identified counterparts) exhibited by individuals. Along with the disparities in their pictures, the individuals in both case companies seemed to acknowledge the 'essential traits' of each company's network picture (atomized vs. inter-connected), positioning (individualistic vs. collectivistic) and strategic orientation (direct vs. indirect functions), integrating those traits in their interaction with suppliers. As such, the diversity of individual pictures seems an inevitable consequence of the different preoccupations of individuals and functional areas and can be a source of strength as well as weakness in interaction. Thus, in line with previous work (e.g. Ramos \& Ford, 2011), the research emphasizes the importance for managers to appreciate these differences and the eventual costs and benefits of stimulating information sharing to build consensual pictures of companies supplier networks.

The paper also enriches the concept of network picture both as a research and managerial tool. This research indicates that the extent to which actors are aware of the existence of direct and indirect counterparts, or their "network horizon" is an insufficient indicator of what they actually "know" about their indirect counterparts. In fact, similar network horizons may form the boundaries for substantially different and more or less clear or comprehensive network pictures. Adding to the work of Ramos et al. (2005) and Ramos and Ford (2011), this paper suggests that in order to draw a finer definition of companies' actual network pictures, other aspects besides the number of indirect partners must be included, namely their network 
positioning, the nature of the resources and activities used and the type of relationships connecting the actors.

Our concluding remark points to one of the most important findings that resulted from this study: there is a distinction between the actors that companies see as relevant, and the actors they interact with. In order to have a clearer picture of how industrial networks are organized, interpreted and acted upon by companies, it would be useful to make this distinction more obvious. In this paper we suggest that an "interaction net" can be identified corresponding to the set of actors that a company is aware of (network horizon - Holmen \& Pedersen, 2003), those it sees as relevant (network context or focal net - Möller \& Halinen, 1999) and additionally, those with which it interacts. This interaction net concept corresponds to the most restricted set of actors that companies actually interact with. The "interaction net" concept may be used by researchers as a tool to obtain a finer understanding of how networks work. It can also be used by companies as a managerial device for interrogating the link between their network pictures and interaction strategies, making clearer its implications for their position and direction.

\subsection{Study limitations and suggestions for future research}

It is important to note a limitation to this study, and to all other research on the connections between actors' sense-making and interaction processes. This paper has concentrated on the perceptions or pictures held by "customer companies". Business interaction is by definition at least dyadic and all "supplier relationships" are simultaneously "customer relationships". All business interaction is an evolving process that occurs within a wider pattern of interaction stretching across the network. The interaction approaches, relationship management and supplier strategies of actors are not individually determined, but instead are outcomes of multiple expectations, interpretations and interaction episodes. These multiple factors suggest caution in interpreting any findings about interaction, positioning or strategy that are based on research located in only one side of dyads and on a limited number of the many interconnected and mutually significant dyads. For instance, our cases suggest that suppliers' beliefs about their customers' expectations may impact on their intentions to inform the client about changes that can occur in their bundle of resources or in their connections to other actors.

Thus, future research is needed to further explore the interconnections between customer and supplier network pictures. Although our findings may also apply in other settings, future studies on other types of networks are required to confirm our findings. Those studies could focus on cases that are intermediate to our 'ideal type' cases. Future studies could also focus on cases of different settings or sectors, such as professional services or distribution that may encompass different strategies and interactions; on customer networks, where the impact of customers' connections with other suppliers or with their own customer may be more easily recognized and integrated in companies' network pictures and interaction strategies.

\section{Annex A. Interview scripts}

\section{Customer company's interview scripts}

Phase 1: Network picture, positioning and corporate and supplier strategy

Topic1: Customer company's history and positioning

Aim: Identify the informants' views on: the evolution of company's positioning and strategy and its underlying causes (e.g. competitors, industry dynamics, internal resources and capabilities). As we wanted to capture the companies' idiosyncratic evolutionary paths (of which we had limited knowledge), this specific script was intentionally lightly structured (Fontana \& Frey, 1994).
- Tell us about your company (e.g., activities, history)

- How would you describe your company strategy? Has it changed? If so, why?

- Who are your main competitors? Why?

- How would you describe your industry? Has it changed? How?

Topic 2: Positioning and supplier strategy

Aim 1: Understand the company's supplier strategy and the role attributed to suppliers.

- How important are suppliers to your company's success? Which is their role?

- Has the importance of suppliers to your company's success changed over time?

- Which are your company's main supplier criteria (e.g. price, quality, innovation)?

- Did the supply criteria changed over time? Why?

- Will suppliers' role change in the future? Why and how?

- Generally, do the suppliers' counterparts influence the relationship between your company and the suppliers? If so, how?

Aim 2: Define the company's strategy and interaction with each supplier in the study

- What do you buy from supplier X?

- What were you expecting to get from him (e.g. efficiency, innovation)? Did those expectations change? Why?

- Which is the role of supplier X in relation to your company's (e.g. activities, resources)? Has his role changed? Why and how?

- What are your expectations regarding the relationship between your company and supplier $\mathrm{X}$ in the future? Why?

Phase 3: Knowledge and relevance of, and interaction with suppliers' counterparts

Aim 1: Identify level/relevance of knowledge of suppliers' counterparts and monitoring strategy

- Can you name any of supplier X's suppliers, customers or other partners?

- What do you know of your suppliers' counterparts?

- How did you know of those suppliers' counterparts?

- Is it important for your company to know of its suppliers' counterparts? Why?

- Were these information considered when selecting the suppliers? Is it important to the relationship between the supplier and your company? Why?

- Can you remember a specific situation when that knowledge was useful? Explain.

- Would it be useful to know more about your suppliers' counterparts? Why?

Aim 2: Identify the relevance attributed to the supplier's counterparts; characterize the interaction between the company and the suppliers' counterparts.

- Does your company interact with your suppliers' counterparts?

- Are those interactions regular or sporadic? Why did they occur?

- What are the goals of interactions with suppliers' counterparts? Give examples.

- Did those interactions have any benefits or disadvantages for your company?

Suppliers' interview script (Phase 2)

Topic 1: Relationship between the supplier and the customer company.

Aim: Understand the informants' views on the evolution of the relationship between its company and the customer company 
- What do you sell to the customer company (Adira or Vulcano)?

- When did you start selling to the customer company?

- How has the relationship with the customer company evolved? Why?

- What are your expectations regarding the relationship between your company and the customer company in the future? Why?

Topic 2: Customer knowledge of and interaction with suppliers' counterparts

Aim 1: Identify the customer company's level of knowledge of suppliers' counterparts

- Does the customer know any of your suppliers, customers or other partners?

- How did the customer know of those counterparts? Does he ask you about them?

- For your firm, does it matter if the customer knows of your counterparts? Why?

- Was or is that knowledge important in the relationship between your company and the customer? Why?

- Can you remember a specific situation when that knowledge was useful? Explain.

- Can you identify your main suppliers and clients? What are you buying from or selling to them (.e.g. products, services) and what types of resources and activities are involved in those relationships?

Aim 2: Identify the interaction between the customer and the supplier's counterparts.

- Does the customer interact with your suppliers or clients?

- Are those interactions regular or sporadic? Why did they occur? Exemplify.

- Did those interactions have any benefits or disadvantages for your company? And for the customer company? If so, please explain.

\section{Annex B}

Table B1. Adira case: Excerpts of interview coding

\footnotetext{
Network pictures

"Our strongest competitors are not ahead of us due to the components that they use, because they buy exactly the same things we buy. The difference is that they have lots of people working in development and a strong internal ability to work all the machinery details. While we, due to our wide portfolio of machines, struggle with those details and are really behind them in those aspects" Adira - Engineering Manager

"We have a serious problem with the Subcontracted Suppliers: we must to do everything internally because the national subcontractors are either too expensive or have an awful quality. We can only outsource things that are not minimally critical." Adira - Subcontracted Buyer

"Local representatives of international manufacturers are incompetent. They are not negligent or lazy. They are incompetent because they don't know! They are generally unable to help us" Adira - Engineering Manager
}

"The client is buying an Adira machine: he's not buying a Siemens command, together with a Rofin generator and with an Adira structure. I need to have all the capabilities inside to give a complete response to the entire machine." Adira - Engineering Manager

"We have always manufactured according to Adira's specifications. We don't have a say and we don't want to. They give us an order, we make it and that's it." Adira Supplier SAS

"Adira is not open for suppliers to participate in the technological development of their products. They have probably more to lose than to gain with that. But that is Adira's philosophy and I wouldn't like to meddle with that." Adira - Supplier FCGC

"They [Adira] don't ask us to develop. (...) Adira is a large organization, a major exporter with a consolidated team, but everything is truly oriented inward." Adira - Supplier - SAC

"Our internal philosophy is to respond to the customer as the sole counterpart When I arrived back in the 70s, Adira was already developing its internal capabilities to reduce its dependence on its external counterparts. This effort has been constantly pursued till we achieved our own autonomy" Adira - CEO
Positioning: Perceived impact of suppliers' counterparts

"I'm really not worried to know who Cybelec [the numerical command supplier] buys its components from" Adira - Engineering Manager

"... when he [a subcontracted supplier] had orders to deliver to other clients, he used to give those other clients the priority and let us hanging to dry." Adira Production Manager

"The work we send him [a subcontracted supplier]... he can even get it done by someone else as long as it is well done. We pay the price that was defined. I don't care where he makes it". Adira - Subcontracted Buyer

"Much more important than knowing who the suppliers are buying from is to know who they are supplying, because that immediately gives us an idea of their reputation." Adira - Engineering Manager

Strategy: Orientation of suppliers' strategy (customer's expectations)

"Nowadays, delivery lead times must be very flexible. I think all manufacturers are aware of that and we also make it clear to our suppliers." Adira - Components Buyer

"We control what they [subcontracted suppliers] must manufacture and their priorities... Each subcontracted supplier can be contacted several times a day and we tell them: "now I want that part, now make that and that"... and this allows us to overcome some of our planning problems or to respond to extremely short deliver lead times" Adira - Production Manager

"Besides reliability, we also look for components that can be found anywhere in the world to be sure that if we need a component locally [to assist a customer in an export market], it will be easy to find. That also allows us to keep low inventories, even because customers do not accept to wait one or two months to get a component." Adira - Engineering Manager

Strategy: Monitoring approach

"It's something rather invisible. For instance, at the hydraulic level, we know that some of our suppliers buy from other hydraulic suppliers and just put a label on the parts they don't have... but we don't have much access to our suppliers' suppliers. Sometimes we open the parts and we see that they are buying here and there. But we don't have much information; we don't normally know we are suppliers buy from." Adira - Engineering Manager

"Let's imagine that we are buying a new command from Cybelec. Knowing that a reputed machinery manufacturer uses it give us some confidence to buy. If they are buying is because potential problems have been already solved, otherwise they wouldn't integrate that new command. That kind of information is important" Adira - Engineering Manager

"The need to know who the suppliers' clients are is stronger when we don't know the suppliers or if they don't have a solid market reputation. Knowing who their clients are give us some security. There are companies, whose reputation assures that they have a fantastic organization and that their suppliers are fully controlled. (...). In other cases, there are companies that already have a solid reputation and whom we don't ask "who are your clients?"” Adira Production Manager

Interaction: Direct and indirect interaction with indirect counterparts

"We made a deal with them [the subcontracted suppliers] that was almost an exclusivity deal. We told them that we didn't want them to work for our competitors. They could find other clients... but as they had always lots of work and were working in their full capacity, they never tried to find new customers." Adira - Logistics Manager

"Sometimes, we don't say how we are using the part. We can't pass that knowledge on because of that suspicion. It is not because we have something to complain about, even because they don't tell us anything about the others [the suppliers' other clients]. But, sometimes, unintentionally, they can give away information that is very important to us and took us years to find." Adira - CEO

"If I wanted to get new customers, I would be in trouble with Adira; because, sometimes, they could want their parts and if the parts weren't ready, it would be troublesome. I know it would because I know guys that created problems like that." Adira - Supplier SMS

Table B2. Vulcano case: Excerpts of interview coding

\section{Network picture}

"This is like a cycling race. At his moment, we lead the race, but we need to have a pool of R\&D capabilities to keep that competitive edge. In order to assure the growth of our sales and the innovation of our products we need to concentrate in our core business - instant production of hot water, and to involve suppliers and other research partners. What we have here is a kind of Interest Grouping - not of firms but of capabilities. We complement the capabilities we have in-house with the capabilities that we have in this pool of associations. Basically, they're our advanced guard." Vulcano - Board Director 
"Currently, there is a philosophy in the group [Bosch] to involve the suppliers as early as possible and we are constantly reminded of that need. We have a group of people here and we produce millions of equipments of different ranges each year. We cannot do everything and, clearly, without our suppliers we wouldn't be able to introduce new models constantly, as we do." Vulcano Development Manager

\section{Positioning: Approach to positioning}

"Currently, this guy from our Development Department is a headache to our suppliers. He is incapable of completing the development of a part without talking with the suppliers and getting some feedback (as small as it may be) from them." Vulcano - Purchasing Manager

"I think that there must be a constant search for new processes and new ways to do things in order to reduce costs from both sides [buyer and supplier] in order to respond to the market's growing demand of flexibility." Vulcano - Logistics Manager

"We know how to do many things well, but Silencor is specialized in stamped metallic parts and TPE in mold injection. We clearly get better parts because we involve our suppliers in the development process." Vulcano - Development Manager

\section{Positioning: Perceived impact of suppliers' relationships}

"The problem is that the auto industry is very centripetal, they are extremely overwhelming with the suppliers, they weave a web around the suppliers and they become super-dependent. Even if their shares are relatively small, the deadlines, the penalties if the production lines stops, all those gears that they have... If their volume is big or similar to ours, they become a priority to the suppliers; there is no doubt about that." Vulcano - Purchasing Manager

"So, I force them to have alternative clients that always bring indirect advantages: the supplier gets to know different markets, new technologies, new parts and new types of demands. There are always synergies to obtain when the supplier has more than one customer." Vulcano - Purchasing Manager

"So, the bottom line is that I don't care where the supplier buys it from. I probably know but I don't really care, because it's all specified from the start." Vulcano Purchasing Manager

"[Suppliers'] Clients are important. When we are selecting a new supplier, that factor makes us have more or less trust in the supplier. (...) In the case of Renco, the Spanish supplier of electronics we selected last year, it was very important to know that they already supplied Bosch-Siemens. It gave us same warranties as Bosch-Siemens' quality standards regarding the suppliers are similar to ours." Vulcano - Development Manager

\section{Strategy: Orientation of suppliers' strategy (customer's expectations)}

"Development is an extra service of the supplier that constitutes a differentiation edge regarding other suppliers". Vulcano - Development Manager

"I think that what is important is their [the suppliers] know-how, their historic and the price." Vulcano - Quality Manager

"Geographically, I think we should have them nearby to have an immediate support in logistics, quality and development. It's very important. We want to change a part and the guy is 10 min or an hour away." Vulcano - Purchasing Manager

"Vulcano thinks that a passive supplier, which doesn't provide solutions or ideas, is not a bad supplier... is an awful supplier." Vulcano - Supplier FTCB

"We are investing in the development area because we have to. It does not bring us any added value ... only for the customer. But we are really forced to do it [by Vulcano] to keep the customer." Vulcano - Supplier FAH

"The greatest benefit we provide Vulcano is our ability to co-develop the parts with them: Because, when it comes to production, we are not that competitive." Vulcano - Supplier FSN

Interaction: Monitoring approach

"If one of our suppliers is working for... let's say our neighbors from Renault or something of the kind, as this type of clients are very demanding, the supplier knows that it [the link with Renault] may valuable to us and he tell us that." Vulcano - Development Manager

"Knowing their supplier structure well is not dramatic in the kind of parts that we buy. Because all that is safeguarded quite well with our specifications. For instance, in a stamped part, we state that the stainless steel or the brass is that one and that one and that it has to be delivered with a certificate." Vulcano Purchasing Manager

"Normally, we use solutions that already exist. In the Celsius project, we adapted a part that Fundiven was already supplying. It had a different construction, but what they chose was not relevant. And regarding the other suppliers is more or less the same. Thus, in many cases, it is not that important to know who supplies our suppliers." Vulcano - Development Manager

"Every year, they [Vulcano] send us these forms [the Supplier Profile] that we have to fill telling them who our other clients are". Vulcano - Supplier GNF

"Yes, they [Vulcano] asks us who our other clients are. They never told me why they want to know but I think it is because they want to know their weight in relation to our other clients, if they have the priority, they want to know. Questions are never innocent" Vulcano - Supplier GNF
Interaction: Direct and indirect interaction with indirect counterparts

"I often tell the suppliers "you need to get more customers, hire a salesman, hit the market and get more customers". If they ask me to help them, I tell them that I can't because I want them to find customers that are different from Bosch". Vulcano - Purchasing Manager

"We don't need to debate issues with a third party. We talk with our suppliers and they know what they can or cannot do. Normally, our relationship is with our supplier. It's preferable like that because the more people are involved in the process the more complicated it becomes. We only involve more people if strictly necessary. But if I can work only with my supplier, it is better for me." Vulcano - Purchasing Manager

"Well, if I tried really hard, I could tell you that we get to know some of our suppliers' suppliers. But it's more to know their working conditions than to get work with them. And even that is quite rare." Vulcano - Purchasing Manager

"My direct supplier is Renco that will buy plastic parts from TPE. If I'll have a complaint it's Renco that I'll be talking to. If I have any problems with the plastic parts, it's Renco I'll be talking to, not with TPE. If we start making by-passes I don't know if this will work." Vulcano - Quality Manager

\section{References}

Ahonen, P., \& Salmi, A. (2003). Portfolios in supply network management: An analysis of a Finish company in the electro-technical industry. 19th IMP Conference, Lugano.

Anderson, J. C., Håkansson, H., \& Johanson, J. (1994). Dyadic business relationships within a business network context. Journal of Marketing, 58(4), 1-15.

Banerji, K., \& Sambharya, R. B. (1998). Effects of network organization on alliance formation: A study of the Japanese automobile ancillary industry. Journal of International Management, 4(1), 41-57.

Batt, P., \& Purchase, S. (2004). Managing collaboration within networks and relationships. Industrial Marketing Management, 33(3), 169-174.

Beverland, M., \& Lindgreen, A. (2010). What makes a good case study? A positivist review of qualitative case research published in industrial marketing management, 1971-2006. Industrial Marketing Management, 39(1), 56-63.

Blakenburg, D. (1992). Kopplade relationer i industriella nätverk. Licenciate Thesis, Uppsala University.

Bond, E. U., III, Houston, M. B., \& Tang, Y. (2008). Establishing a high-technology knowledge transfer network: The practical and symbolic roles of identification. Industrial Marketing Management, 37(6), 641-652.

Cook, K. S., \& Emerson, R. M. (1978). Power, equity and commitment in exchange networks. American Sociological Review, 43(5), 721-739.

Corsaro, D., Ramos, C., Henneberg, S., \& Naudé, P. (2011). Actor network pictures and networking activities in business networks: An experimental study. Industrial Marketing Management, 40(6), 919-932 Special Issue.

Cousins, P., \& Spekman, R. (2003). Strategic supply and the management of inter and intra organizational relationships. Journal of Purchasing and Supply Management, 9(11), 19-29.

Denzin, N., \& Lincoln, Y. (2000). Handbook of qualitative research. (2nd edition). London: Sage Publications.

Dubois, A., \& Araujo, L. (2004). Research methods in industrial marketing studies. In Håkan Håkansson, Debbie Harrison, \& Alexandra Waluszewski (Eds.), Rethinking marketing: Developing a new understanding of markets. (pp. 207-228)Chichester: John Wiley \& Sons [Chap. 1].

Dubois, A., \& Araujo, L. (2007). Case research in purchasing and supply management: Opportunities and challenges. Journal of Purchasing \& Supply Management, 13(3), 170-181.

Dubois, A., \& Gadde, L. -E. (2002). Systematic combining: An abductive approach to case research. Journal of Business Research, 55(7), 553-560.

Dubois, A., Gadde, L. -E., Hulthèn, K., Jonsson, P., \& Sundquist, V. (2003). Supply network flexibility. 20th IMP conference, Copenhagen.

Dubois, A., \& Gilbert, M. (2010). From complexity to transparency: Managing the interplay between theory, method and empirical phenomena in IMM case studies. Industrial Marketing Management, 39(1), 129-136.

Dubois, A., \& Pedersen, A. -C. (2002). Why relationships do not fit into purchasing portfolio models: A comparison between the portfolio and the industrial network approach. European Journal of Purchasing E Supply Management, 8(1), 35-42.

Eisenhardt, K. (1989). Building theories from case study research. Academy of Management Review, 14(4), 532-550.

Eisenhardt, K., \& Graebner, M. (2007). Theory building from cases: Opportunities and challenges. Academy of Management Journal, 50(1), 25-32.

Fereday, J., \& Muir-Cochrane, M. (2006). Demonstrating rigor using thematic analysis: A hybrid approach of inductive and deductive coding and theme development. International Journal of Qualitative Methods, 5(1), 80-92.

Fontana, A., \& Frey, J. F. (1994). Interviewing: The art of science. In handbook of qualitative research. In Norman K. Denzin, \& Yvonna S. Lincoln (Eds.), (1st edition). London: Sage Publications [Chap. 22].

Ford, D., Gadde, L. -E., Håkansson, H., Lundgren, A., Snehota, I., Turnbull, P., et al. (1998). Managing business relationships. Chichester: John Wiley \& Sons.

Ford, D., Gadde, L. -E., Håkansson, H., \& Snehota, I. (2002). Managing networks. 18th IMP Conference. Perth, Australia.

Ford, D., Gadde, L. -E., Håkansson, H., \& Snehota, I. (2003). Managing business relationships. (2nd edition). Chichester: John Wiley \& Sons Ltd.

Ford, D., Gadde, L. -E., Håkansson, H., \& Snehota, I. (2011). Managing business relationships. (3rd edition). Chichester: John Wiley \& Sons Ltd. 
Ford, D., \& MacDowell, R. (1999). Managing business relationships by analyzing the effects and value of different actions. Industrial Marketing Management, 28(5) 429-442.

Ford, D., \& Mouzas, S. (2010). Networking under uncertainty: Concepts and research agenda. Industrial Marketing Management, 39(6), 956-962.

Ford, D., \& Redwood, M. (2005). Making sense of network dynamics through network pictures: A longitudinal case study. Industrial Marketing Management, 34(7). 648-657.

Gadde, L. -E., \& Håkansson, H. (2003). Strategizing in industrial networks. Industrial Marketing Management, 32(5), 357-364.

Gattorna, J. L., \& Walters, D. W. (1996). Managing the supply chain: A strategic perspective. London: McMillan Press.

Geiger, S., \& Finch, J. (2010). Networks of mind and networks of organizations: The map metaphor in business network research. Industrial Marketing Management, 39(3), 381-389.

Gibbert, M., Ruigrok, W., \& Wicki, B. (2008). What passes as a rigorous case study? Strategic Management Journal, 29, 1465-1474.

Glaser, B., \& Strauss, A. (1967). The discovery of grounded theory: Strategies in qualitative research. London: Wiedenfeld and Nicholson.

Gulati, R. (1999). Network location and learning: The influence of network resources and firm capabilities on alliance formation. Strategic Management Journal, 20(5), 397-420.

Gulati, R., Nohria, N., \& Zaheer, A. (2000). Strategic networks. Strategic Management Journal, 21(3), 203-215.

Håkansson, H., \& Ford, D. (2002). How should companies interact in business networks? Journal of Business Research, 55(2), 133-139.

Hakansson, H., Ford, D., Gadde, L. -E., Snehota, I., \& Waluszeski, A. (2009). Business in networks. Chichester: John Wiley.

Håkansson, H., \& Johanson, J. (1993). Industrial functions of business relationships. Advances in International Marketing, 5, 13-29.

Håkansson, H., \& Snehota, I. (1995). Developing relationships in business networks. London: Routledge.

Henneberg, S. C., Mouzas, S., \& Naudé, P. (2006). Network pictures: Concepts and representations. European Journal of Marketing, 40(3-4), 408-429.

Henneberg, S., Mouzas, S., \& Naudé, P. (2010). Sense-making and management in business networks: Some observations, considerations, and a research agenda. Industrial Marketing Management, 39(3), 355-360.

Holmen, E., Håkansson, H., \& Pedersen, A. -C. (2003). Framing as a means to manage supply network. Journal of Customer Behaviour, 2, 385-407.

Holmen, E., \& Pedersen, A. -C. (2001). Knowledge and ignorance of connections between relationships. 17th IMP conference, Oslo.

Holmen, E., \& Pedersen, A. -C. (2003). Strategizing through analyzing and influencing the network horizon. Industrial Marketing Management, 32(5), 409-418.

Jarillo, J. C. (1988). On strategic networks. Strategic Management Journal, 9, 31-41.

Jårvensivu, Y., \& Törnroos, J. A. (2010). Developing case study research with moderate constructionism and abduction: Conceptualization and a practical illustration. Industrial Marketing Management, 39(1), 100-108.

Kaplan, A., \& Goldsen, J. (1965). The reliability of content analysis categories. In Harold D. Lasswell, \& Nathan Leites (Eds.), Language of politics: Studies in quantitative semantics (pp. 83-112). Cambridge: MIT Press Chap. 5.

Krippendorff, K. (2004). Content analysis. Thousand Oaks: Sage Publications.

Leek, S., \& Mason, K. (2009). Network pictures: Building an holistic representation of a dyadic business-to-business relationship. Industrial Marketing Management, 38(6), 599-607.

Leek, S., \& Mason, K. (2010). The utilization of network pictures to examine a company's employees' perceptions of a supplier relationship. Industrial Marketing Management, 39(3), 400-412.

Lincoln, Y. (1991). The arts and sciences of program evaluation. Evaluation Practice $12(1), 1-7$.

Liu, R. J., \& Brookfield, J. (2000). Stars, rings and ties: Organizational networks and their dynamics in Taiwan's machine tool industry. Long Range Planning, 33, 322-348.

Mattsson, L. -G., \& Johanson, J. (1992). Network positions and strategic action. In Bjorn Axelsson, \& Geoffrey Easton (Eds.), Industrial networks: A new view of reality (pp. 205-217). London: Routledge [Chap. 11].

Mattsson, L. -G. (2002). Reorganisation of distribution in globalisation of markets. 18th IMP conference, Perth.

Miles, M. B., \& Huberman, A. M. (1994). Qualitative data analysis: An expanded sourcebook. London: Sage Publications.

Möller, K., \& Halinen, A. (1999). Business relationships and networks: Managerial challenge of network era. Industrial Marketing Management, 28(5), 413-427.
Möller, K., \& Törrönen, P. (2003). Business supplier's value creation potential: A capability-based analysis. Industrial Marketing Management, 32, 109-118.

Powell, W. W. (1990). Neither market nor hierarchy: Network forms of organization. Research in Organizational Behavior, 12, 295-336.

Punch, K. (2005). Introduction to social research: Quantitative and qualitative approaches. London: Sage Publications.

Ragin, C. C. (2000). Fuzzy-set social science. London: The University of Chicago Press.

Ramos, C. (2008). Developing network pictures as a research tool: capturing the output of individuals sense-making in organisational networks. Unpublished PhD Thesis, University of Bath, School of Management.

Ramos, C., \& Ford, D. (2011). Network pictures as a research device: Developing a tool to capture actors' perceptions in organizational networks. Industrial Marketing Management, 40(3), 447-464

Ramos, C., Ford, D., \& Naudé, P. (2005). Developing network pictures as a conceptual device. 1st meeting of the IMP journal, Oslo.

Ramos, C., Henneberg, S., \& Naudé, P. (2012). Understanding network picture complexity: an empirical analysis of contextual factors. Industrial Marketing Management, 41(6), 951-972.

Ritchie, J., \& Lewis, J. (2003). Qualitative research practice: A guide for social sciences students and researchers. London: Sage Publications.

Ritter, T., \& Ford, D. (2004). Interactions between suppliers and customers in business markets. In Häkan Håkansson, Debbie Harrison, \& Alexandra Waluszewski (Eds.) Rethinking marketing: Developing a new understanding of markets (pp. 99-115). London: Wiley Chap 6.

Ritter, T., Wilkinson, I., \& Johnston, W. J. (2004). Managing in complex business networks. Industrial Marketing Management, 33(3), 175-183.

Rubin, H. J., \& Rubin, I. S. (1995). Qualitative interviewing: The art of hearing data. London: Sage Publications.

Snehota, I. (1990). Notes on a theory of business enterprise. Unpublished PhD thesis, Uppsala University, Department of Business Studies, Uppsala.

Snehota, I. (2004). Perspectives and theories of market. In Häkan Håkansson, Debbie Harrison, \& Alexandra Waluszewski (Eds.), Rethinking marketing: Developing a new understanding of markets (pp. 15-32). London: Wiley [Chap. 1].

Stake, R. (1994). Case studies. In Norman K. Denzin, \& Yvonna S. Lincoln (Eds.), Handbook of qualitative research (pp. 236-247). (1st edition). London: Sage Publications [Chap. 14].

Stake, R. E. (1995). The art of case study research. London: Sage Publications.

Strauss, A., \& Corbin, J. (1990). Basics of qualitative research: Grounded theory, procedures and techniques. London: Sage Publications.

Strauss, A., \& Corbin, J. (1998). Basics of qualitative research techniques and procedures for developing grounded theory. London: Sage Publications.

Walsh, J. M., \& Ungson, G. R. (1991). Organizational memory. Academy of Management Review, 16(1), 57-91.

Walter, A., Müller, T. A., Helfert, G., \& Ritter, T. (2003). Functions of industrial supplier relationships and their impact on relationship quality. Industrial Marketing Management, 32(2), 159-169.

Weick, K. E. (1995). Sensemaking in organizations. Thousand Oaks: Sage Publications.

Wilkinson, I., \& Young, L. (2002). On cooperating firms, relations and networks. Journal of Business Research, 55(2), 123-132.

Yin, R. (1994). Case study research: Design and methods. (2nd edition). London: Sage Publications.

Yin, R. K. (2009). Case study research: Design and methods. (4th edition). London: Sage Publications.

Catarina Roseira is an Assistant Professor of Marketing, Strategy and Entrepreneurship at the Faculty of Economics - University of Porto and at the EGP-UPBS (Porto Business School). Her primary areas of research are in strategy and networks, B2B marketing and entrepreneurship.

Carlos Brito is an Associate Professor of Marketing at the Faculty of Economics - University of Porto and at the EGP-UPBS (Porto Business School). He is Pro-Rector for Innovation and Entrepreneurship at the University of Porto. His primary areas of research are in networks, B2B marketing and relationship marketing.

David Ford is an Affiliate Professor at Euromed-Management, Marseille. He is a Founder Member of the IMP Group of Researchers. His primary areas of research are into the structure and process of business networks. 